\section{Previne Brasil, Agência de Desenvolvimento da Atenção Primária e Carteira de Serviços: radicalização da política de privatização da atenção básica?}

\author{
Previne Brasil, the Agency for the Development \\ of Primary Healthcare, and the Services Portfolio: \\ radicalization of privatization policy in basic \\ healthcare?
}

\author{
Marcia Valeria Guimarães Cardoso Morosini 1 \\ Angelica Ferreira Fonseca 1 \\ Tatiana Wargas de Faria Baptista 2
}

\title{
Resumo
}

O ensaio analisa documentos produzidos pelo Ministério da Saúde entre 2019 e 2020 para a reorganização da atenção básica: a nova política de financiamento (Previne Brasil), a Agência de Desenvolvimento da Atenção Primária à Saúde (Lei no 13.958), a Carteira de Serviços e normatizações complementares. Buscou-se compreender como as mudanças projetadas nas funções gestoras e no modelo de atenção à saúde contribuem para o fortalecimento da lógica mercantil na política pública. Tomamos como parâmetros de análise as atribuições gestoras e os princípios e diretrizes do Sistema Único de Saúde (SUS) e de uma atenção básica orientada pela determinação social do processo saúde/doença, a concepção ampliada de saúde, o cuidado territorializado, o enfoque comunitário e a coordenação do cuidado numa rede integrada. As mudanças na alocação dos recursos públicos, a instituição de novas possibilidades de relação entre o Estado e empresas privadas e a adequação do modelo de atenção às particularidades da gestão de mercado revelam o sentido privatizante dessas medidas. A política assume um enfoque individualizante no que tange ao modelo de atenção e financiamento, enfraquecendo a perspectiva do território, o trabalho comunitário, o cuidado integral e multidisciplinar. Acelera-se a reconfiguração do SUS no sentido de um sistema no qual agentes públicos ou privados podem participar, indiferenciadamente, aprofundando a ruptura com o compromisso constitucional da saúde como dever do Estado.

Gestão em Saúde; Política de Saúde; Estratégia Saúde da Família; Sistema Único de Saúde; Atenção Primária à Saúde

\author{
Correspondência \\ M. V. G. C. Morosini \\ Escola Politécnica de Saúde Joaquim Venâncio, Fundação \\ Oswaldo Cruz. \\ Av. Brasil 4365, sala 322, Rio de Janeiro, RJ 21040-360, Brasil. \\ mvgcmorosini@gmail.com
1 Escola Politécnica de Saúde Joaquim Venâncio, Fundação Oswaldo Cruz, Rio de Janeiro, Brasil.
2 Escola Nacional de Saúde Pública Sergio Arouca, Fundação Oswaldo Cruz, Rio de Janeiro, Brasil.




\section{Introdução}

Desde a sua instituição, o desenvolvimento do Sistema Único de Saúde (SUS) vem sendo acompanhado pelo crescimento do setor privado que, a princípio, figuraria com papel complementar e suplementar no atendimento à saúde 1,2 . Sob a hegemonia da racionalidade neoliberal, a lógica privatista tem forçado a ampliação da sua presença no SUS, passando progressivamente a compor a tessitura do sistema. Incorporaram-se ideias afeitas às relações de mercado nos desenhos das políticas e nos processos de gestão, impondo limites à universalização do direito, à concepção ampliada de saúde e à base de financiamento da seguridade social.

A atenção básica - principal frente de expansão do direito à saúde na vigência do SUS - não foi isenta desse desenvolvimento meandroso. Difundiram-se noções de racionalização de recursos e produtividade articuladas à lógica gerencialista. Instituíram-se dispositivos por meio dos quais o Estado transferiu parte dos recursos e funções ao setor privado, caso dos contratos de gestão firmados entre municípios e Organizações Sociais (OS), para oferta e gestão de serviços e da força de trabalho 3,4.

Esse processo não aconteceu sem resistência. O SUS preserva, disputando seu direcionamento e apontando para um horizonte societário mais justo e igualitário, os princípios da universalidade, integralidade e equidade. Entretanto, desde 2016 constituiu-se um contexto ainda mais favorável à pauta privatista que é materializada em contrarreformas deflagradas em diversas frentes das políticas sociais e em específico na saúde. Discursos e medidas adotadas explicitam a hegemonia da perspectiva de mercado na formulação das políticas do setor 5,6, tendo como alvo preferencial a atenção básica.

Mudanças importantes foram introduzidas em 2017, com a Portaria no 2.436, que instituiu a nova Política Nacional de Atenção Básica (PNAB) 7, num processo de reestruturação que abrange diretrizes, formas de organização dos serviços, composição das equipes, processo de trabalho e escopo de práticas, com impactos sobre o modelo de atenção e o direito à saúde. Relativiza-se a universalidade, recomendando a cobertura de $100 \%$ da população apenas em áreas de grande dispersão territorial, áreas de risco e vulnerabilidade social; desenha-se a segmentação do cuidado pela oferta de padrões diferenciados de serviços (básico e ampliado); desloca-se a Estratégia Saúde da Família (ESF) de sua posição central para a organização da atenção básica, admitindo composições de equipe e carga horária que retomam a chamada "atenção básica tradicional" 8 .

A partir de 2019, a reconfiguração do SUS pela atenção básica foi intensificada por meio de um conjunto de medidas que evidenciam a constituição de uma nova política, mais ampla do que as alterações introduzidas pela PNAB. Compõe-se de mudanças que abrangem nomenclatura, reestruturação organizacional e produção de instrumentos normativos.

A atenção básica passou a figurar nos documentos do Ministério da Saúde denominada como atenção primária à saúde (APS). Retoma-se a nomenclatura internacional - APS - desconsiderando o esforço de diferenciação no sentido de afirmar a atenção básica como um campo compromissado com a universalidade e a integralidade ${ }^{9}$, em sintonia com os princípios do SUS e em contraposição às orientações restritivas e seletivas hegemônicas em nível global, atualmente articuladas à noção de cobertura universal 10,11.

Em maio de 2019, o Ministério da Saúde adotou uma nova estrutura organizacional com extinção e rearranjo de secretarias. A Secretaria de Atenção à Saúde (SAS) foi desmembrada em três: a Secretaria de Atenção Primária à Saúde (SAPS), a Secretaria de Atenção Especializada à Saúde (SAES) e a Secretaria Especial de Saúde Indígena (SESAI). Alçada à condição de secretaria, a APS passou a ser objeto de intensa produção de normativas.

No segundo semestre de 2019, apresentaram-se três eixos de reestruturação para a atenção básica: financiamento, regulação e prestação de serviços. Em relação às medidas, apontamos críticas quanto ao processo e conteúdo das propostas, destacando as características que, articuladamente, promovem um modelo mercantilizado de gestão e atenção à saúde.

No que tange ao financiamento, a proposta começou a circular a partir de julho de 2019, em apresentações realizadas por gestores da SAPS/Ministério da Saúde. A primeira apresentação ocorreu no Congresso Brasileiro de Medicina de Família e Comunidade e continuou em encontros estaduais, numa articulação com o Conselho Nacional de Secretários de Saúde (CONASS). Nenhum documento oficial foi apresentado para debate e a metodologia de cálculo não foi disponibilizada até a reunião da Comissão Intergestores Tripartite (CIT) de 31 de outubro, data de aprovação. Esse processo dificultou 
a construção de cenários para a análise do novo modelo, desconsiderando solicitações do Conselho Nacional de Saúde (CNS) e outras entidades, para maior explicitação e aprofundamento da discussão.

A nova proposta de financiamento, Programa Previne Brasil 12, altera de forma estrutural a lógica indutiva de organização da política de saúde e aporta três mudanças principais para a atenção básica: extingue os pisos fixo e variável (PAB); introduz o repasse dos recursos federais pelo número de pessoas cadastradas; e estabelece nova forma de pagamento por desempenho.

Sobre a regulação do sistema, em agosto do mesmo ano, o Ministério da Saúde encaminhou para o Congresso Nacional a Medida Provisória (MP) no 890 13, convertida em dezembro na Lei no 13.958 14, que institui o Programa Médicos pelo Brasil (PMB) e autoriza a criação da Agência para Desenvolvimento da Atenção Primária à Saúde (ADAPS), instituição de direito privado, com modalidade paraestatal (Serviço Social Autônomo).

Quanto à prestação e provisão de serviços, também em agosto, o Ministério da Saúde apresentou a proposta da Carteira de Serviços para a APS (CaSAPS) 15, estabelecendo a relação de serviços a serem ofertados pela atenção básica. Nesse caso, o Ministério da Saúde abriu consulta pública por uma semana e, após quatro meses, divulgou o documento consolidado 16.

A estratégia política adotada tem sido a apresentação das propostas em momentos diferentes, enunciadas isoladamente e com tempos acelerados para discussão. Gestadas simultaneamente aos debates preparatórios para a 16a Conferência Nacional de Saúde, tais propostas não foram apresentadas neste âmbito. Do mesmo modo, o CNS e os conselhos estaduais e municipais foram secundarizados nesse processo.

A perda de influência do CNS, ou seja, do controle social, e o fortalecimento dos fóruns de gestores, em particular a CIT, vem ocorrendo desde os anos 1990 17. Os temas da política de saúde são excluídos do ambiente participativo, restringindo-se à arena de pactuação entre gestores, transitando para a condição de problemas de gestão, cujas respostas são construídas em ambientes técnicos e administrativos, ocultando os interesses políticos mobilizados.

Esse conjunto de medidas aprofunda o sentido das mudanças estabelecidas pela PNAB 2017 e delineia uma alteração significativa no cenário político e institucional da atenção básica. O Previne Brasil 12, a ADAPS 14 e a CaSAPS 16, combinados sinergicamente, ampliam as possibilidades de privatização da saúde e integram um novo processo de acumulação, alargado pela abertura do setor ao capital estrangeiro 18 , ocorrida em 2015. Elementos normativos complementares 19,20,21,22,23 foram publicados pelo Ministério da Saúde, ratificando as medidas e preenchendo eventuais lacunas. A articulação entre seus conteúdos e a velocidade com que esses documentos foram oficializados sugerem que a arquitetura da nova política para a atenção básica vem sendo produzida com clareza de interesses.

Reconhecida como nicho de expansão do capital, a atenção básica precisa ser convertida em espaço que proporciona oportunidades diversificadas de mercantilização, o que requer a conjugação de manobras de expropriação do público e apropriação pelo privado. Esse processo aproxima-se do que Harvey 24 descreveu como acumulação via espoliação, no qual o Estado atua impondo medidas tais como alteração ou criação de marcos regulatórios, fazendo regredir ao domínio privado e às relações de mercado direitos conquistados pela classe trabalhadora.

Este ensaio analisa documentos produzidos pelo Ministério da Saúde entre 2019 e 2020 para a reorganização da atenção básica: o Previne Brasil, a Lei no 13.958 que institui a ADAPS, a CaSAPS e normatizações complementares (Quadro 1). Buscou-se compreender como tais mecanismos, de modo combinado, promovem mudanças nas funções gestoras do SUS e no modelo de atenção à saúde, contribuindo para o fortalecimento da lógica mercantil na política pública. Para analisá-los retomamos as atribuições gestoras (planejamento, financiamento, regulação, execução de serviços) e os princípios e diretrizes do SUS (universalidade, integralidade, descentralização e participação social) 25 , atualizados pelo debate de uma atenção básica orientada pela determinação social do processo saúde/doença, a concepção ampliada de saúde, o cuidado territorializado, o enfoque comunitário e a coordenação do cuidado numa rede integrada 26 . 
Quadro 1

Instrumentos legais e normativos orientadores das mudanças em curso na atenção básica, publicados pelo Ministério da Saúde, entre agosto de 2019 e janeiro de 2020 .

\begin{tabular}{|c|c|c|c|}
\hline $\begin{array}{l}\text { Instrumentos legais e } \\
\text { normativos }\end{array}$ & Objetivo & Destaques & Comentários principais \\
\hline $\begin{array}{l}\text { Lei no } 13.958 \text { 14, de } \\
18 \text { de dezembro de } \\
2019 \text { - convertida da } \\
\text { Medida Provisória no } \\
89013 \text {, de } 1 \text { o de agosto } \\
\text { de } 2019\end{array}$ & $\begin{array}{l}\text { Institui o Programa Médicos } \\
\text { pelo Brasil (PMB), no âmbito } \\
\text { da atenção primária à } \\
\text { saúde no Sistema Único de } \\
\text { Saúde, e autoriza o Poder } \\
\text { Executivo federal a instituir } \\
\text { serviço social autônomo } \\
\text { denominado Agência para } \\
\text { o Desenvolvimento da } \\
\text { Atenção Primária à Saúde } \\
\text { (ADAPS). }\end{array}$ & 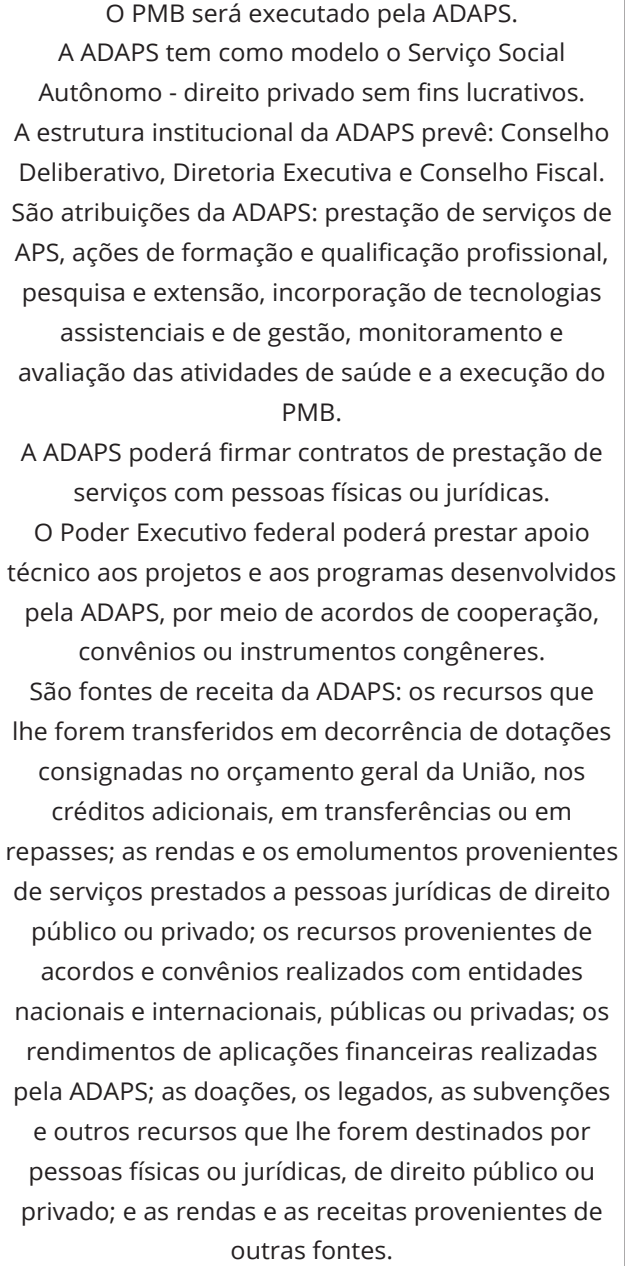 & $\begin{array}{l}\text { Permite importante transferência } \\
\text { de responsabilidades gestoras } \\
\text { do Ministério da Saúde para a } \\
\text { ADAPS. Torna a atenção básica } \\
\text { espaço para a atuação direta das } \\
\text { empresas privadas de saúde na } \\
\text { assistência, com acesso a fontes } \\
\text { públicas, estáveis e volumosas de } \\
\text { financiamento. }\end{array}$ \\
\hline
\end{tabular}

(continua) 
Quadro 1 (continuação)

\begin{tabular}{|c|c|c|c|}
\hline $\begin{array}{l}\text { Instrumentos legais e } \\
\text { normativos }\end{array}$ & Objetivo & Destaques & Comentários principais \\
\hline $\begin{array}{l}\text { Portaria no } 2.539 \text { 19, } \\
\text { de } 26 \text { de setembro } \\
\text { de } 2019\end{array}$ & $\begin{array}{l}\text { Institui a equipe de atenção } \\
\text { primária (eAP) e dispõe } \\
\text { sobre o financiamento da } \\
\text { equipe de saúde bucal (eSB). }\end{array}$ & $\begin{array}{l}\text { Estabelece que a eAP pode ser constituída somente } \\
\text { por médico e enfermeiro. } \\
\text { Flexibiliza a carga horária e a população adscrita das } \\
\text { eAP em: } \\
\text { Modalidade I - 20h semanais e população adscrita } \\
\text { correspondente a 50\% da população adscrita para } \\
\text { uma equipe de saúde da família (eSF); } \\
\text { Modalidade II - 30h semanais e pop. adscrita } \\
\text { correspondente a 75\% da população adscrita para } \\
\text { uma eSF. } \\
\text { Permite a participação de profissionais das eAP e de } \\
\text { eSB (Modalidade I com carga horária diferenciada) } \\
\text { em mais de uma equipe. } \\
\text { Permite a composição de eSB na Modalidade I, nos } \\
\text { seguintes termos: } \\
\text { Modalidade I - 20h: eSB composta por profissionais } \\
\text { com carga horária mínima individual de } 20 \text { horas } \\
\text { semanais e cadastrados em uma mesma unidade } \\
\text { de saúde, com população adscrita correspondente a } \\
50 \% \text { da população adscrita para uma eSF; ou } \\
\text { Modalidade I - 30h: eSB composta por profissionais } \\
\text { com carga horária mínima individual de } 30 \text { horas } \\
\text { semais e cadastrados em uma mesma unidade } \\
\text { de população adscrita para uma eSF. }\end{array}$ & $\begin{array}{c}\text { Permite e favorece a criação de } \\
\text { equipes compostas somente por } \\
\text { médicos e enfermeiros, com carga } \\
\text { horária e cobertura populacional } \\
\text { flexibilizadas em relação às eSF, } \\
\text { contribuindo para enfatizar o } \\
\text { enfoque biomédico e enfraquecer a } \\
\text { perspectiva territorial na AB. }\end{array}$ \\
\hline
\end{tabular}

(continua) 
Quadro 1 (continuação)

\begin{tabular}{|c|c|c|c|}
\hline $\begin{array}{l}\text { Instrumentos legais e } \\
\text { normativos }\end{array}$ & Objetivo & Destaques & Comentários principais \\
\hline $\begin{array}{l}\text { Portaria no } 2.979 \text { 12, } \\
\text { de } 12 \text { de novembro } \\
\text { de } 2019\end{array}$ & $\begin{array}{c}\text { Institui o Programa Previne } \\
\text { Brasil, que estabelece novo } \\
\text { modelo de financiamento de } \\
\text { custeio da atenção primária } \\
\text { à saúde no âmbito do } \\
\text { Sistema Único de Saúde. }\end{array}$ & $\begin{array}{l}\text { O financiamento federal de custeio da atenção } \\
\text { primária à saúde (APS) será constituído por: } \\
\text { I - capitação ponderada; II - pagamento por } \\
\text { desempenho; e III - incentivo para } \\
\text { ações estratégicas. } \\
\text { O cálculo dos incentivos financeiros da capitação } \\
\text { ponderada considera: I - a população cadastrada } \\
\text { na equipe de saúde da família (eSF) e equipe } \\
\text { de atenção primária (eAP) no Sistema de } \\
\text { Informação em Saúde para a Atenção Básica } \\
\text { (SISAB); II - a vulnerabilidade socioeconômica } \\
\text { da população cadastrada na eSF e na eAP; III - o } \\
\text { perfil demográfico por faixa etária da população } \\
\text { cadastrada na eSF e na eAP; e IV - classificação } \\
\text { geográfica definida pelo Instituto Brasileiro de } \\
\text { Geografia e Estatística (IBGE). } \\
\text { o cálculo do incentivo financeiro do pagamento } \\
\text { por desempenho será efetuado considerando os } \\
\text { resultados de indicadores alcançados pelas equipes } \\
\text { credenciadas no Sistema do Cadastro Nacional de } \\
\text { Estabelecimentos de Saúde (SCNES). } \\
\text { a prólculo para a definição dos recursos financeiros } \\
\text { parancentivo às ações estratégicas deverá } \\
\text { cosão em ações estratégicas em saúde. }\end{array}$ & $\begin{array}{l}\text { Extingue o piso de atenção básica } \\
\text { fixo (PAB fixo), eliminando o } \\
\text { único mecanismo de repasse de } \\
\text { recursos per capita. A capitação } \\
\text { ponderada por lista de pacientes } \\
\text { favorece a contratação de serviços } \\
\text { ao setor privado e afasta-se da } \\
\text { perspectiva do direito universal } \\
\text { à saúde. A lógica do pagamento } \\
\text { por desempenho deixa de ser } \\
\text { complementar e firma-se como um } \\
\text { dos eixos centrais. }\end{array}$ \\
\hline
\end{tabular}

(continua) 


\begin{tabular}{|c|c|c|c|}
\hline $\begin{array}{l}\text { Instrumentos legais e } \\
\text { normativos }\end{array}$ & Objetivo & Destaques & Comentários principais \\
\hline $\begin{array}{l}\text { Portaria no } 3.222 \text { 20, } \\
\text { de } 10 \text { de dezembro } \\
\text { de } 2019\end{array}$ & \begin{tabular}{|} 
Dispõe sobre os indicadores \\
do pagamento por \\
desempenho, no âmbito do \\
Programa Previne Brasil.
\end{tabular} & $\begin{array}{l}\text { Apresenta apenas sete indicadores da clínica/ } \\
\text { epidemiologia para o “Pagamento por } \\
\text { Desempenho”, relativos às ações estratégicas de } \\
\text { saúde da mulher, pré-natal, saúde da criança e } \\
\text { hipertensão arterial e diabetes mellitus para 2020: } \\
\text { I - proporção de gestantes com pelo menos } 6 \\
\text { (seis) consultas pré-natal realizadas, sendo a 1ª } \\
\text { até a 20ª semana de gestação; II - proporção de } \\
\text { gestantes com realização de exames para sífilis e } \\
\text { HIV; III - proporção de gestantes com atendimento } \\
\text { odontológico realizado; IV - cobertura de exame } \\
\text { citopatológico; V - cobertura vacinal de poliomielite } \\
\text { inativada e de pentavalente; VI - percentual de } \\
\text { pessoas hipertensas com pressão arterial aferida } \\
\text { em cada semestre; e VII - percentual de diabéticos } \\
\text { com solicitação de hemoglobina glicada. } \\
\text { Define as ações estratégicas para } 2021 \text { e 2022: } \\
\text { I - ações multiprofissionais no âmbito da atenção } \\
\text { primária à saúde; II - ações no cuidado puerperal; } \\
\text { III - ações de puericultura (crianças até } 12 \text { meses); IV } \\
\text { - ações relacionadas ao HIV; V - ações relacionadas } \\
\text { ao cuidado de pessoas com tuberculose; VI - } \\
\text { ações odontológicas; VII - ações relacionadas às } \\
\text { hepatites; VIII - ações em saúde mental; IX - ações } \\
\text { relacionadas ao câncer de mama; e X - indicadores } \\
\text { globais de avaliação da qualidade assistencial e } \\
\text { experiência do paciente. }\end{array}$ & $\begin{array}{l}\text { Adota poucos indicadores que, } \\
\text { embora relevantes, restringem-se } \\
\text { ao escopo de ações tradicionais que } \\
\text { não ultrapassam a prevenção de } \\
\text { base biomédica. Não contribui para } \\
\text { a valorização da promoção à saúde } \\
\text { e da abrangência do cuidado. }\end{array}$ \\
\hline $\begin{array}{l}\text { Carteira de Serviços } \\
\text { da Atenção Primária } \\
\text { à Saúde (CaSAPS), de } \\
18 \text { de dezembro de } \\
201916\end{array}$ & \begin{tabular}{|} 
Descrever, para a população, \\
para os demais níveis do \\
sistema, para os gestores \\
e para os profissionais que \\
atuam na APS, a lista de \\
ações e serviços clínicos \\
e de vigilância em saúde \\
ofertados no âmbito da \\
APS brasileira.
\end{tabular} & $\begin{array}{l}\text { Define o leque de serviços disponíveis e ofertados } \\
\text { pelas unidades de APS, separados da seguinte } \\
\text { forma: "Vigilância em Saúde", "Promoção à } \\
\text { Saúde”, "Atenção e Cuidados Centrados na Saúde } \\
\text { do Adulto e do Idoso", "Atenção e Cuidados } \\
\text { Centrados na Saúde da Criança e do Adolescente”, } \\
\text { "Procedimentos na APS" e "Atenção e Cuidados } \\
\text { Relacionados à Saúde Bucal”. } \\
\text { Faculta ao gestor municipal acrescentar ou retirar } \\
\text { itens da Carteira de Serviços. }\end{array}$ & $\begin{array}{l}\text { A carteira de serviços é } \\
\text { fundamental para a precificação, } \\
\text { condição para o processo de } \\
\text { contratação de serviços ao } \\
\text { setor privado. Tem um caráter } \\
\text { indicativo (sugestivo) e seu } \\
\text { conteúdo converge para a ideia } \\
\text { de segmentação do cuidado e } \\
\text { estabelecimento de mínimos, } \\
\text { típicos da APS seletiva. }\end{array}$ \\
\hline $\begin{array}{l}\text { Portaria no } 3.51021 \text {, } \\
\text { de } 18 \text { de dezmebro } \\
\text { de } 2019\end{array}$ & $\begin{array}{c}\text { Institui incentivo financeiro } \\
\text { de custeio adicional mensal } \\
\text { para municípios com } \\
\text { equipes de saúde da família } \\
\text { ou equipes de saúde bucal } \\
\text { que sejam campo de prática } \\
\text { para a formação } \\
\text { de profissionais no } \\
\text { âmbito da APS. }\end{array}$ & $\begin{array}{l}\text { Considera formação profissional no âmbito da APS } \\
\text { o programa de residência em medicina de família } \\
\text { e comunidade para os profissionais de Medicina, } \\
\text { ou o programa de residência nas modalidades } \\
\text { uniprofissional ou multiprofissional em atenção } \\
\text { primária à saúde ou saúde da família para os } \\
\text { profissionais de odontologia ou enfermagem. }\end{array}$ & $\begin{array}{c}\text { No diálogo entre formação e } \\
\text { gestão, reitera a ideia de que os } \\
\text { profissionais médico, enfermeiro } \\
\text { e odontólogo são suficientes } \\
\text { para compor a perspectiva } \\
\text { multiprofissional na atenção básica. }\end{array}$ \\
\hline
\end{tabular}

(continua) 
Quadro 1 (continuação)

\begin{tabular}{|c|c|c|c|}
\hline $\begin{array}{l}\text { Instrumentos legais e } \\
\text { normativos }\end{array}$ & Objetivo & Destaques & Comentários principais \\
\hline $\begin{array}{l}\text { Nota Técnica no } 322 \text {, } \\
\text { de } 27 \text { de janeiro de } \\
2020\end{array}$ & $\begin{array}{l}\text { Apresenta a configuração do } \\
\text { Núcleo Ampliado de Saúde } \\
\text { da Família e Atenção Básica } \\
\text { (NASF-AB) e Programa } \\
\text { Previne Brasil. }\end{array}$ & $\begin{array}{c}\text { A composição de equipes multiprofissionais deixa } \\
\text { de estar vinculada às tipologias de equipes NASF-AB. } \\
\text { O gestor municipal passa a ter autonomia para } \\
\text { compor suas equipes multiprofissionais, definindo } \\
\text { os profissionais, a carga horária e os } \\
\text { arranjos de equipe. } \\
\text { A partir de janeiro de } 2020 \text {, o Ministério da Saúde } \\
\text { não realizará mais o credenciamento } \\
\text { de NASF-AB. }\end{array}$ & $\begin{array}{l}\text { Explicita a renúncia ao NASF como } \\
\text { modelo para o fortalecimento } \\
\text { do cuidado multiprofissional } \\
\text { territorializado, decorrente } \\
\text { do seu desfinanciamento } \\
\text { pelo Ministério da Saúde. Não } \\
\text { apresenta uma orientação } \\
\text { alternativa para a compreensão da } \\
\text { multidimensionalidade na } \\
\text { atenção básica. }\end{array}$ \\
\hline $\begin{array}{l}\text { Portaria no } 99 \text { 23, de } 7 \\
\text { de fevereiro de } 2020\end{array}$ & $\begin{array}{c}\text { Redefine registro das } \\
\text { equipes de atenção } \\
\text { primária e saúde mental } \\
\text { no Cadastro Nacional de } \\
\text { Estabelecimentos de Saúde } \\
\text { (CNES). }\end{array}$ & $\begin{array}{c}\text { Reformula a classificação de equipes de saúde. } \\
\text { Apresenta a correlação entre a classificação } \\
\text { anterior e a nova. } \\
\text { Reformula o modelo de informação - } \\
\text { módulo equipes. } \\
\text { Reformula o serviço especializado da } \\
\text { atenção primária. } \\
\text { Modifica a classificação de Motivo de Desativação } \\
\text { de Equipes de Saúde. } \\
\text { Transfere a realização das regras de consistência } \\
\text { relacionadas à composição das equipes, carga } \\
\text { horária e outras que sejam necessárias ao } \\
\text { gerenciamento das equipes de saúde de atenção } \\
\text { primária e de saúde mental, do CNES para sistema } \\
\text { de gestão e monitoramento sob a responsabilidade } \\
\text { da Secretaria de Atenção Primária à Saúde } \\
\text { (SAPS)/Ministério da Saúde. }\end{array}$ & $\begin{array}{c}\text { Reinsere a possibilidade de } \\
\text { cadastro de equipe Núcleo } \\
\text { Ampliado de Saúde da Família } \\
\text { (NASF) no CNES. } \\
\text { Introduz modificações na } \\
\text { classificação das equipes e } \\
\text { códigos, com repercussões para } \\
\text { os procedimentos de alimentação } \\
\text { de dados. Isto acarreta nova carga } \\
\text { de trabalho que, no período de } \\
\text { adaptação, pode gerar dificuldades } \\
\text { aos municípios, com implicações } \\
\text { para o financiamento. } \\
\text { A mudança de responsabilidade } \\
\text { pelas regras de consistência - do } \\
\text { CNES para sistema ainda não } \\
\text { publicamente constituído - requer } \\
\text { atenção. Note-se que foi cancelado } \\
\text { o Programa Nacional de Melhoria } \\
\text { do Acesso e da Qualidade da } \\
\text { Atenção Básica (PMAQ), sistema } \\
\text { que monitorava a atenção básica. }\end{array}$ \\
\hline
\end{tabular}

Fonte: elaboração das autoras. 


\section{Previne Brasil: induzindo a focalização}

Três argumentos foram apresentados para justificar a nova política de financiamento: atender a demanda de maior autonomia dos gestores municipais no uso dos recursos federais; alcançar os grupos mais vulneráveis; garantir custo-efetividade na política de atenção básica.

No que tange à maior autonomia do gestor municipal, o que se apresenta no Previne Brasil é muito mais uma mudança no que é objeto do incentivo federal e seus propósitos do que uma ruptura com a lógica indutiva.

Desde a Norma Operacional Básica de 1996, vigorava o modelo de financiamento baseado num mecanismo de transferência regular e automático dos recursos federais - o PAB - com repasse fundo a fundo. Todo município passou a receber de forma imediata um recurso per capita/ano para custeio das ações básicas de saúde (PAB fixo) e incentivos para a implantação de programas recomendados pelo Ministério da Saúde (PAB variável), como os Programas Saúde da Família (PSF) e de Agentes Comunitários (PACS). A criação do PAB permitiu a superação, no âmbito da atenção básica, do modelo de pagamento por produção de serviços e estimulou a adesão dos municípios à ESF 27.

Alçada à condição de estratégia prioritária para a reorientação do modelo, impulsionada pelos recursos do PAB, a ESF alcançou expansão notável. Entre 1998 e 2019, transitou de 25,7\% de municípios com PSF para 98,6\% com ESF 28,29. Pode-se inferir que o Ministério da Saúde obteve sucesso na ampliação de cobertura e na organização do sistema no nível local. O mesmo não se pode afirmar quanto à garantia do acesso e à integralidade do cuidado, embora se reconheça o esforço de fortalecimento da atenção básica e os diferentes incentivos e ações para seu aprimoramento 30,31,32.

Ao definir o incentivo financeiro como indutor para a mudança da organização da atenção, o gestor federal assumiu papel central na orientação da política no âmbito local, com autonomia limitada para o gestor municipal no uso do recurso federal. O modelo de financiamento adotado - modelo das "caixinhas" 33 - foi um ponto de tensão entre gestores federal e municipal quanto à diretriz da descentralização. Os recursos transferidos pela União eram "carimbados”, conforme as políticas priorizadas pelo Ministério da Saúde 33. De 1996 a 2019, esse modelo passou por diferentes revisões, sem alterar a lógica de indução do modelo de atenção a partir do repasse federal.

Na última revisão do modelo de financiamento, em 2017 (Projeto SUS Legal) 34, a mudança buscava, em algum grau, afastar-se da lógica indutora. Constituíram-se dois grandes blocos - custeio e investimento - para o repasse dos recursos. Os PAB fixo e variável foram mantidos no bloco de custeio, com um rol de incentivos específicos vinculados ao $\mathrm{PAB}$ variável.

O Previne Brasil aporta uma mudança mais radical. Extingue o PAB fixo - única transferência intergovernamental em saúde com base populacional - o que implica, segundo Massuda 35, o fim do financiamento universal da atenção básica. Os critérios que passam a orientar a nova política de financiamento são: a capitação ponderada; o pagamento por desempenho e o incentivo para ações estratégicas 12 .

Desde a Lei Orgânica da Saúde, a lógica do planejamento ascendente, com base territorial e populacional, apresentava-se como mecanismo de orientação e, para a grande maioria dos municípios, o valor fixo no repasse de recursos era a principal garantia para a organização de um SUS local. No modelo de base populacional havia a possibilidade do gestor, com aquele montante, estabelecer a distribuição dos recursos conforme o perfil de cada território, considerando as desigualdades. No contexto de desfinanciamento 36 produzido pela Emenda Constitucional no 95 (EC 95) 37, somada às ameaças de extinção do piso da saúde e à desvinculação de recursos, configura-se um grande risco para a manutenção dos sistemas locais. Ainda que o valor do PAB fixo estivesse defasado 27,33, sua manutenção representava alguma garantia de continuidade de recursos para a organização da atenção básica.

A capitação ponderada proposta no Previne Brasil é calculada considerando-se: (1) a população cadastrada na equipe de saúde da família ou equipe de atenção primária; (2) a vulnerabilidade socioeconômica da população cadastrada; (3) o perfil demográfico por faixa etária da população cadastrada; e (4) a classificação geográfica definida pelo Instituto Brasileiro de Geografia e Estatística (IBGE) 12. A população cadastrada corresponde ao "resultado da multiplicação do número de equipes de SF e de AP, credenciadas e cadastradas no Sistema de Cadastro Nacional de Estabelecimentos de Saúde (SCNES), pelo quantitativo potencial de pessoas cadastradas por equipe, não podendo ultrapassar a população total definida 
pelo IBGE" 12. Em tese, conjuga dois elementos: a ênfase na pessoa cadastrada e o balanceamento pelas condições de vulnerabilidade.

A ênfase na pessoa cadastrada ou assistida 22 desperta a preocupação quanto ao enfoque no indivíduo, em detrimento da perspectiva comunitária e da atenção territorializada. Agrava a ruptura com o princípio da universalidade, admitindo que parte da população não será atendida na atenção básica, e evoca a ideia de cobertura universal, com direcionamento de recursos escasseados para os segmentos mais pobres da população, promovendo um modelo de APS focalizante.

Ao aludir à vulnerabilidade socioeconômica, à composição etária das pessoas cadastradas e à classificação geográfica dos municípios pelo IBGE para a ponderação no processo de capitação, a proposta aparentemente remete à ideia de equidade. Entretanto, o próprio IBGE alerta para os limites desse estudo, indicando tratar-se de uma "primeira aproximação" que não abrange as várias dimensões de território, devendo ser apropriada em outros níveis de análise 38. Talvez por isso não seja possível depreender as relações entre essa classificação e a compreensão dos fenômenos no campo da saúde.

Desse modo, a ênfase na pessoa assistida, desconsiderando o processo social e político de produção das vulnerabilidades, tende a tornar menos visíveis os problemas territoriais e a desmobilizar ações do campo da saúde que transcendam a clínica biomédica.

Um estudo do Conselho de Secretarias Municipais de Saúde do Estado do Rio de Janeiro (COSEMS-RJ) projetou dois cenários para 2020, com base apenas na análise da adoção do componente de capitação ponderada pelos municípios do estado. O primeiro, compreendendo a situação de cadastro atual, mostrou perda de $37,15 \%$ do repasse federal total para esses municípios. O segundo cenário simulou o máximo de cadastramento possível, considerando a capacidade instalada e os parâmetros estabelecidos, perfazendo um repasse final com redução de 4,68\% 39. Assim, ainda que os municípios fossem capazes de cumprir a meta de cadastramento, possibilidade pouco provável para vários, isto seria insuficiente para manter o montante de recursos recebido em 2019.

Esforços como o realizado pelo COSEMS-RJ enfrentaram a dificuldade imposta pela celeridade do debate e pela não divulgação prévia da base de dados e da metodologia de cálculo utilizadas pelo Ministério da Saúde.

Um segundo aspecto do novo modelo é o pagamento por desempenho, "considerando os resultados de indicadores alcançados pelas equipes credenciadas e cadastradas no SCNES" 12 . O pagamento por desempenho já vinha sendo praticado na atenção básica desde 2011, por meio do Programa Nacional de Melhoria do Acesso e da Qualidade da Atenção Básica (PMAQ), que aliava a ampliação do acesso ao acompanhamento e a discussão de indicadores. Aportava um novo recurso, somado ao PAB, possibilitando investimentos em reforma e ampliação de unidades 40. O Previne Brasil não valoriza os aprendizados do PMAQ e introduz outra lógica de desempenho, que enfatiza o monitoramento de procedimentos e os resultados das ações de saúde, não abarcando a avaliação dos processos de trabalho.

Para regulamentar o pagamento por desempenho, em novembro de 2019, a CIT aprovou a Portaria no 3.222 definindo somente sete indicadores de desempenho para 2020 20, relacionados a alguns aspectos clínicos que abrangem mulheres, crianças, hipertensos e diabéticos. Nessa Portaria não foram especificadas as metas, nem os parâmetros para pagamento por desempenho, exigindo nova regulamentação.

Diferentemente do Reino Unido, principal experiência internacional utilizada como referência, o Previne Brasil adota os critérios de capitação e desempenho como mecanismo de cálculo para a transferência intergovernamental e, não, como mecanismo de remuneração de serviços. Massuda 35 alerta para possíveis dificuldades na adoção desse novo procedimento e implicações para a sustentabilidade da atenção básica pelos municípios. Mendes \& Carnut 36 lembram que o modelo inglês, antes de assumir tal formato, sofreu vários ajustes não considerados para a formulação da política brasileira. Além disso, há diferenças importantes entre os sistemas de saúde e as realidades nacionais que precisam ser consideradas na adoção de políticas de financiamento, notadamente a desigualdade estrutural que marca a formação social brasileira.

As desigualdades sociais, territoriais e assistenciais no Brasil exigem um modelo que considere as dificuldades e vulnerabilidades existentes, orientando-se pela equidade. Tal modelo não pode perder de vista a perspectiva da construção da igualdade de direitos e a universalidade, compromissos que deveriam guiar as políticas de gestão do SUS e, em particular, o papel redistributivo do financiamento 
federal. Sem esse horizonte, orientar-se pelas vulnerabilidades sociais afasta-se da equidade e transmuta-se em focalização e restrição de direitos.

O terceiro componente é o pagamento por incentivo para ações estratégicas, com dezesseis itens que recuperam alguns componentes do PAB variável, prevendo a inclusão de outros conforme atos normativos posteriores 12 . Mantém-se a lógica de indução por incentivos específicos, mas extinguemse aqueles incentivos que reforçavam a orientação do modelo e a estruturação do trabalho na lógica territorial e comunitária, como a implantação de equipes de saúde da família, Núcleo de Apoio à Saúde da Família (NASF) e saúde indígena. Essas modalidades são reinseridas como equipes para registro no SCNES na Portaria no 99 23, de fevereiro de 2020, entretanto, não recuperam o status de estratégias incentivadas pela política federal de financiamento da atenção básica.

Tomando como referência o NASF, pretere-se uma importante estratégia de construção da integralidade e do cuidado ampliado territorializado. Parte significativa de suas responsabilidades consiste em apoiar e articular serviços e equipes nas ações e práticas a serem adotadas no território, atuando de forma a integrar a comunidade, a rede de cuidados e as políticas de outros setores.

\section{ADAPS: configurando os mecanismos de ampliação da privatização}

A Lei no 13.95814 opera um duplo movimento: institui o PMB, no âmbito da APS, e autoriza a criação da ADAPS, que será responsável pela execução do programa.

O PMB é apresentado com a finalidade de incrementar a prestação de serviços médicos em locais de difícil provimento ou alta vulnerabilidade e fomentar a especialização em medicina de família e comunidade. É anunciado como uma contraposta substitutiva ao Programa Mais Médicos (PMM), a fim de "corrigir a distribuição de vagas anteriormente definida pelo programa" 41.

A ADAPS é proposta como uma alternativa à gestão pública que busca conferir "segurança jurídica à execução da política" e "sustentabilidade econômica para a sua implementação" 41. É configurada como um serviço social autônomo, pessoa jurídica "de direito privado sem fins lucrativos, de interesse coletivo $e$ utilidade pública”, cuja finalidade seria promover a execução de políticas de desenvolvimento da APS em âmbito nacional ${ }^{41}$. Dentre as atribuições previstas estão: prestação de serviços, ações de formação e qualificação profissional, pesquisa e extensão, incorporação de tecnologias assistenciais e de gestão, monitoramento e avaliação das atividades de saúde e a execução do PMB.

Sua estrutura institucional prevê um Conselho Deliberativo, uma Diretoria Executiva e um Conselho Fiscal. O Conselho Deliberativo é apresentado como o "órgão de deliberação superior da ADAPS" 14, composto por 12 representantes: seis do Ministério da Saúde; um do CONASS; um do Conselho Nacional de Secretarias Municipais de Saúde (CONASEMS); um da Associação Médica Brasileira; um do Conselho Federal de Medicina; um da Federação Nacional dos Médicos; e um do CNS.

Ressalte-se a predominância de instâncias representativas da gestão - Ministério da Saúde com voto de qualidade para desempate, CONASS e CONASEMS - e de entidades médicas. O CNS e as entidades médicas não estavam previstos na $M P$ no 890 , que incluía representação do setor privado. Essa nova composição não necessariamente amplia a representação do interesse público na gestão da ADAPS, uma vez que o controle social dispõe de somente um representante e que os três segmentos da representação profissional médica incluídos têm forte proximidade aos interesses privatistas na saúde. Segundo Giovanella et al. 42, foram apresentadas mais de 300 emendas à MP, mas recomendações em favor do SUS não foram contempladas no relatório da Comissão Especial que a analisou e seu sentido geral prevaleceu no texto da Lei. Esse registro é importante para explicitar as intenções da proposta e a existência da contraposição.

Instituindo a ADAPS foram criadas condições para que uma entidade privada assuma a gestão da atenção básica, incluindo a captação de recursos de outras fontes. Justifica-se pela necessidade de dar suporte ao PMB, mas o escopo de atribuições extrapola significativamente esta finalidade, constituindo uma nova e ampla porta de entrada para o setor privado no SUS. Concordamos com Giovanella et al. 42 que indicam a perspectiva privatista da MP e o risco de uma dupla terceirização que aqui caracterizamos pela transferência de competências de gestão da atenção básica para a ADAPS e pela possibilidade desta agência contratar prestação de serviços de empresa pública ou privada, possibilidade festejada pelo setor de saúde suplementar 43. 
Disponibiliza-se ao setor privado acesso e gestão de fonte estável e volumosa de financiamento, constituída por receitas previstas para a ADAPS: recursos transferidos da União, recursos provenientes de serviços prestados a pessoas jurídicas públicas ou privadas e recursos decorrentes de contratos, acordos e convênios com entidades nacionais e internacionais, públicas ou privadas, abrangendo instituições de ensino, entre outros 14. Registre-se que o SUS mobiliza o segundo maior orçamento da União, com mais de 120 milhões de pessoas dependentes, sendo a produção de serviços pela atenção básica assegurada.

O SUS conformava um espaço importante, porém ainda restrito, de atuação do setor privado, ordenado pelas regras da administração pública. Colocando-se no lugar de mero contratante, o poder público abdica do papel de gestor do sistema. Ficam expostos aos interesses de mercado uma série de obrigações, como a responsabilidade sanitária, o compromisso com o direito e o cuidado em saúde, os resultados promovidos pelo sistema de serviço e o zelo com as informações dos usuários. O setor privado passa a atuar num mercado monopsônio, no qual existe um único comprador - no caso, o Estado - para vários vendedores, com lugar garantido para a saúde suplementar e abertura para outros arranjos. O setor privado contará com o controle de todos os recursos que compõem a gestão - econômico, técnico, informacional, trabalhista (para contratar e dispor dos servidores públicos), educacional e científico -, podendo definir as regras do jogo.

Há na Lei no 13.95814 mecanismos de controle para a atuação da ADAPS, como: previsão de orientação técnica e supervisão do Ministério da Saúde sobre a execução do PMB; contrato de gestão entre ADAPS e Ministério da Saúde; submissão do relatório de atividades à apreciação do Ministério da Saúde e enviado ao Congresso Nacional e CNS; e fiscalização do contrato de gestão pelo Tribunal de Contas da União (TCU). Entretanto, a penalidade prevista para o descumprimento injustificado do contrato de gestão é somente a dispensa do Diretor-Presidente da ADAPS pelo Conselho Deliberativo.

A execução do PMB via ADAPS é justificada também pela "possibilidade da instituição de pagamento por desempenho e exigência de patamares mínimos de qualidade assistencial, por meio do contrato de gestão" 41. O pagamento por desempenho e o estabelecimento da qualidade da atenção em patamares mínimos remetem à complementariedade entre a lógica de privatização impulsionada pela Lei no 13.958 e o conteúdo da CaSAPS.

\section{CaSAPS: reduzindo e adaptando a atenção para a gestão privada}

Em dezembro de 2019, o Ministério da Saúde publicou a CaSAPS 16. Em agosto, a SAPS/Ministério da Saúde apresentou à consulta pública uma proposta dessa Carteira 15. Naquele momento, seu objetivo era "estabelecer um cenário 'ótimo' para a implementação e oferta de serviços clínicos nas unidades de saúde" 15. Essa primeira versão introduzia genericamente os princípios orientadores da APS e estabelecia quatro eixos de organização: (1) acesso de primeiro contato, (2) longitudinalidade, (3) integralidade e abrangência do cuidado, e (4) coordenação/cooperação clínica. O eixo de acesso de primeiro contato, o único extensamente abordado, apresentava o que parecia ser o cerne da proposta: organizar o processo de trabalho, a agenda e propor novos formatos de equipe, centrados em médicos e enfermeiros. A lista de serviços foi apresentada no anexo do documento, assumindo menos destaque, porém evidenciando uma mudança importante, com predomínio de ações e práticas clínicas, de caráter individual e assistencial, com ênfase em patologias e procedimentos.

A reação à proposta foi imediata. A Sociedade Brasileira de Medicina de Família e Comunidade (SBMFC) posicionou-se favoravelmente, alegando a necessidade de maior resolutividade, aferição da qualidade e eficiência dos serviços 44 . A Rede APS 45 apresentou preocupações com o escopo reduzido da atenção, baseado em um modelo clínico e individual, e o desaparecimento da dimensão familiar e comunitária. Ressaltou a funcionalidade da carteira de serviços para o processo de precificação e lembrou que a contratação de prestadores implica a definição do número de pessoas a serem cobertas (capitação por lista de pacientes) e o rol de procedimentos a serem prestados.

O CNS, algumas associações profissionais e instituições científicas posicionaram-se denunciando o enfoque predominantemente biomédico e o distanciamento da perspectiva de saúde integral. O questionamento foi bastante abrangente, contemplando a argumentação, o conteúdo e o modo como a proposta foi produzida. 
O documento final da CaSAPS 16 é bastante diferente daquele posto em consulta. Foi publicado em três versões: uma voltada à população e duas versões voltadas aos gestores e profissionais de saúde - completa e reduzida. O que antes era anexo passou a ser parte central dos documentos e toda discussão sobre a organização do processo de trabalho, agenda e modalidades de equipe foi excluída. Os serviços e ações estão organizados em cinco grupos: "Vigilância em Saúde e Promoção à Saúde", "Atenção e Cuidados Centrados no Adulto e no Idoso", "Atenção e Cuidados Centrados na Criança e no Adolescente", "Procedimentos na APS" e "Atenção e Cuidados Relacionados à Saúde Bucal - Odontologia" 16 . Na versão completa, a cada item estão associados recomendações, material para consulta e indicação dos insumos para a sua implantação.

Não é possível analisar em que grau as contribuições derivadas da consulta pública foram incorporadas, pois não houve publicização dos resultados. Percebe-se uma intenção de desviar das críticas feitas à primeira versão. O documento definitivo tornou-se mais sofisticado em termos de argumentação e fundamentação teórica e mais complexo em relação à descrição e composição dos serviços. Sua direcionalidade ficou mais velada, revelando-se naquilo que não abriu mão de instituir ou desconstruir.

É apresentado como um documento de referência para os gestores, podendo haver ampliação ou supressão dos serviços listados, em função das especificidades locais. Comparada aos parâmetros que vinham orientando a expansão da ESF, expressos em especial nos Cadernos de Atenção Básica (CAB), a CaSAPS representa uma redução em relação ao escopo de ações que vinha sendo fomentado com recursos federais - financeiros e técnicos. Assim, a Carteira já parte de padrões próximos ao mínimo e reitera a segmentação da atenção a partir da oferta diferenciada entre padrões essencial (básico) e ampliado (estratégico), indicados na PNAB 2017. A CaSAPS prevê para 2020 a avaliação de sua implantação, de modo a subsidiar a definição desses padrões. Portanto, indagamos: há na composição da CaSAPS serviços que possam ser preteridos, sem incorrer em desassistência ou perda de capacidade resolutiva?

Analisamos a Carteira com base em quatro aspectos-chave - territorialização, multidisciplinaridade, trabalho comunitário e integralidade do cuidado - indicativos da orientação da atenção básica pela determinação social do processo saúde/doença, a concepção ampliada de saúde, o cuidado territorializado, o enfoque comunitário e a coordenação do cuidado numa rede integrada 26.

A territorialização remete à compreensão dos processos históricos que condicionam a vida e as relações sociais num espaço determinado, considerando as especificidades das situações ambientais, populacionais e as necessidades de saúde ${ }^{46}$. Corresponde a um modo de organização dos serviços e práticas de saúde, com centralidade no território e responsabilidade sanitária. Na CaSAPS, o termo território aparece somente duas vezes, associado à ideia de âmbito local, e territorialização é referido como uma técnica para o levantamento de informações. Essa noção reduzida peca pela ausência de referências aos determinantes sociais e à intersetorialidade, reforçando a perspectiva biomédica de compreensão do processo saúde/doença e de organização da atenção.

O esvaziamento do enfoque da territorialização desdobra-se no enfraquecimento da noção de comunidade - limitada a local ou conjunto de pessoas de uma localidade - perdendo o horizonte de construção de relações entre as equipes e as pessoas das diferentes comunidades. A ideia de orientação comunitária está dissociada da participação popular, expressão que sequer aparece na CaSAPS.

A CaSAPS, ao preterir a participação popular, uma das diretrizes históricas da ESF, em relação direta com o trabalho do ACS, nega aos usuários a condição de sujeitos do processo de organização da atenção. A condição de sujeito remete à noção de integralidade que implica o entendimento do homem em suas várias dimensões - caráter biopsicossocial - e o reconhecimento da determinação social do processo saúde/doença. Não se trata de um atributo que se autodefina. Evocar a integralidade implica necessariamente explicitar orientações e medidas para a sua concretização 47. Na CaSAPS, tais medidas não estão especificadas. Faz-se uso de uma ideia já consagrada, sem se comprometer com sua realização que requereria uma rede de serviços complementares e articulados, previsão de ações intersetoriais e abordagem multidisciplinar.

Se a intersetorialidade permanecia como um desafio notório na atenção básica, o trabalho multidisciplinar conquistou avanços importantes com a incorporação de profissionais de diferentes áreas. A estruturação dos NASF aportou de modo mais sistemático conhecimentos e práticas de nutrição, fisioterapia, assistência social, psicologia, terapia ocupacional, farmácia, educação física, saúde cole- 
tiva que interagiram com as equipes, na perspectiva do cuidado integral. Entretanto, a CaSAPS não faz referência a essa forma de organização do trabalho multidisciplinar, aprofundando a insegurança estabelecida para as equipes NASF, desde a publicação da PNAB 2017, reforçada pelo seu desfinanciamento na Previne Brasil e pela Nota Técnica no 3 de 2020 22. Essa Nota estabelecia: o cancelamento de novos credenciamentos de equipes NASF-AB, o arquivamento das solicitações já enviadas e a desvinculação da composição de equipes multiprofissionais às tipologias de equipes NASF-AB. Ainda que a Portaria no 99 de 2020 tenha reinserido o NASF entre as modalidades para registro de equipes da atenção básica no SCNES, a situação permanece incerta 23.

As menções à multidisciplinaridade/multiprofissionalidade são feitas de modo indiferenciado $\mathrm{e}$ predominantemente associado a condições específicas, como violência à mulher e cuidados paliativos. Um traço importante é sua aparição na introdução do documento, nal qual se afirma o objetivo da CaSAPS: "(...) é um documento que visa nortear as ações de saúde na APS brasileira com forte reconhecimento da clínica multiprofissional" 16 . A multiprofissionalidade aqui se apequena em sua versão exclusivamente clínica que é reiterada nas Portarias no 2.53919 e $n o 3.51021$ de 2019. A primeira institui equipe formada apenas por médico e enfermeiro, a segunda prevê aporte de incentivos financeiros para municípios com equipes que sejam campo de prática para programas de residência médica ou que incluam odontólogos e enfermeiros - mecanismos potentes para difundir a redução da multiprofissionalidade a estes profissionais.

A Portaria no 2.53919 traz mudanças com efeitos também para a continuidade da atenção e a universalidade do acesso. Ao instituir a composição mínima - médico e enfermeiro - para a equipe de atenção primária, a portaria flexibiliza a carga horária e a população adscrita, admitindo duas modalidades de equipes de atenção primária. Para a Modalidade I, estabelece carga horária mínima individual de 20 horas semanais e $50 \%$ da população adscrita a uma equipe de saúde da família; para a Modalidade II, 30 horas semanais e $75 \%$ da população adscrita a uma equipe de saúde da família. Fica permitido aos integrantes das equipes participarem em mais de uma equipe de atenção primária ou equipe de saúde da família.

Essas alterações regulamentam as propostas da PNAB 20177 que admitiu o apoio do Ministério da Saúde a outras equipes, que não a equipe de saúde da família, apontando para carga horária e composição diferenciadas. Essa configuração pode ser atrativa para gestores e grupos profissionais, pela possibilidade de conciliar vínculos de trabalho, porém, é potencialmente nociva para a constituição de vínculos de cuidado entre profissionais e população.

O quase apagamento do agente comunitário de saúde (ACS) na CaSAPS é mais um elemento contundente da desconstrução da equipe de saúde da família, da lógica do trabalho comunitário e da territorialização. Esse trabalhador é mencionado uma única vez, em recomendação relativa ao cuidado ao puerpério. Radicaliza-se, assim, a orientação da PNAB 20177 que deixou de prever um número mínimo desse trabalhador nas equipes de saúde da família e admitiu equipes de atenção básica sem ACS.

O que se projeta no horizonte da saúde ao enfraquecer o trabalho do ACS na atenção básica? Torna-se difícil imaginar, em grande parte do contexto brasileiro, o exercício de um cuidado territorializado que prescinda do trabalho do ACS. Aprofunda-se a distância entre a realidade dos territórios e as equipes e serviços, ampliando barreiras ao acesso das pessoas aos cuidados em saúde. Perde-se, por exemplo, a potencialidade do trabalho educativo produzido em maior sintonia com a dinâmica da vida nas comunidades 8 .

O distanciamento em relação ao território tem outra forma importante de expressão na CaSAPS: a limitação da visita domiciliar a usuários restritos ao domicílio, como recém-nascidos e acamados. A visita domiciliar integra um conjunto de circunstâncias importantes para a criação de vínculos entre os serviços e a comunidade. Baseando-se nela é feito o cadastramento das pessoas e a sua atualização, fundamental para promover o conhecimento sobre as pessoas atendidas e as condições nas quais vivem. Por meio dela, os serviços assumem uma posição ativa quanto à promoção do acesso. Além disso, a visita domiciliar tem sido uma oportunidade de interação subjetiva que permite a observação de condições de risco, vulnerabilidade e sofrimento que não são necessariamente reportados no cotidiano dos serviços.

Afastando-se da perspectiva da atenção territorializada, centrada na comunidade, a CaSAPS põe em perigo atributos que ela mesma cita ao definir APS - como longitudinalidade e coordenação do cuidado. A longitudinalidade requer continuidade da atenção e vínculos duradouros com os usuários 
que, sem uma compreensão mais coletiva, torna-se pouco viável. Igualmente, a ideia da coordenação do cuidado perde bases importantes para o estabelecimento de uma rede de atenção continuada que transcenda a referência e contrarreferência. A organização do cuidado em rede, entendida como compartilhamento do cuidado e complementariedade de responsabilidades, estruturados baseandose no território, com fluxo contínuo de pessoas e informações, necessita de uma concepção de clínica ampliada, pouco afeita a padrões de feições taxonômicas como esses com os quais a CaSAPS pretende organizar a assistência na atenção básica.

É possível reconhecer que os princípios e diretrizes do SUS e da chamada APS forte são tomados de empréstimo nesses documentos como peças retóricas que não se sustentam frente às diretrizes de ordem procedimental adotadas.

A ligação entre as três frentes de mudanças das políticas do campo da atenção básica completa-se aqui. A construção dos meios de aprofundamento da privatização da atenção básica é composta pela redefinição dos mecanismos de financiamento, com destaque para a capitação ponderada e a remuneração por desempenho que, associadas à lista de procedimentos (de extração biomédica), integram os dispositivos necessários à contratualização de entes públicos e privados. Para viabilizar a participação direta do setor privado, em especial da saúde suplementar, na prestação de serviços de atenção básica, com financiamento público, institui-se a ADAPS, constituindo o formato institucional legal para este processo, com efeitos para a gestão, a atenção e a formação em saúde.

\section{Considerações finais}

A atenção básica no Brasil vinha expressando um esforço de construção de um modelo de atenção associado à contínua ampliação do acesso aos serviços e de melhoria da qualidade da atenção. Mais que uma realidade, percebia-se uma aposta de longo prazo, que abarcava uma agenda de enfrentamentos no campo das políticas sociais e do SUS.

Seu financiamento permaneceu insuficiente, com limites e tensões importantes na relação entre os gestores federal e municipal, mas ainda assim foram efetivadas medidas significativas no sentido da descentralização da gestão e da viabilização da atenção local. Com a ESF, confrontou-se mais diretamente o modelo hospitalocêntrico e, ainda que tenhamos avançado menos na superação do modelo biomédico, foi possível produzir um modo multidisciplinar de processo de trabalho. Com a ampliação da composição das equipe de saúde da família e, sobretudo, pela integração com o NASF, concretizaram-se formas inovadoras de interpretar e responder às necessidades de saúde.

Contudo, o viés gerencialista e produtivista da gestão dos serviços e do trabalho consolidou-se em detrimento de um processo de trabalho mais participativo, realizado em equipe, e de uma vinculação mais segura e justa para os trabalhadores, que oferecesse estabilidade e melhores condições para as equipes enfrentarem as mudanças na condução da política. Seus efeitos foram desdobrados no próprio processo de cuidado, fortalecendo práticas e ações passíveis de mensuração, prejudicando a valorização da escuta e a interação subjetiva, características da educação em saúde e igualmente indispensáveis ao exercício da clínica ampliada.

A trama de mudanças para a atenção básica, elaborada em nome de suposta melhoria de eficiência e efetividade na aplicação dos recursos e de resolutividade, revela-se presidida pela racionalidade financeira, que converte a saúde em uma mercadoria ajustável aos interesses do setor privado. Amplia-se a reconfiguração do SUS amparado pela lógica da cobertura universal, que reforça a ideia de um sistema de saúde - cada vez menos único - no qual mais agentes podem participar indiferenciadamente, sejam eles públicos ou privados. Distanciando-se do entendimento da saúde como direito universal, aprofunda-se rapidamente a ruptura com o compromisso constitucional da saúde como dever do Estado.

A acelerada conversão da atenção básica aos interesses mercantis e privatistas no SUS requer mudanças nas modalidades de alocação dos recursos públicos, a instituição de novas possibilidades de relação entre Estado e empresas privadas, e a adequação do modelo de atenção às particularidades da gestão privada. O Governo Federal tem atuado ativamente na produção de normativas que dão sustentação formal e base legal a essa operação. Identifica-se na PNAB 2017 o marco orientador desse 
processo que progressivamente ganha materialidade por meio de um conjunto de medidas produzidas entre 2019 e o início de 2020.

Cumpre um papel importante na transição de uma atenção básica pública para uma atenção básica privatizada, a adesão a uma orientação individualizante quanto ao modelo de atenção e ao processo de trabalho. $\mathrm{O}$ enfoque individualizante é mediado por estratégias que debilitam eixos estruturantes da ESF: a perspectiva do território, a multidisciplinaridade, o trabalho de base comunitária e o cuidado integral. Tais estratégias consistem na composição de equipes que prescindem do ACS, no reforço à ideia de equipe de atenção básica composta principalmente pelos profissionais médico, enfermeiro e odontólogo, no empobrecimento da perspectiva multiprofissional e no enfraquecimento do enfoque comunitário. Associadas à concepção restrita da clínica que orienta a lista de serviços da CaSAPS, essas mudanças consolidam a centralidade do modelo biomédico, mais afeito às práticas de saúde do setor privado.

O financiamento tem poder de induzir as estratégias de mudança pela alocação, restrição ou retirada de recursos. No Previne Brasil, a lógica individualizante é impulsionada pela extinção do PAB fixo e adoção da capitação baseada na pessoa cadastrada e do pagamento por desempenho, centrado em poucos aspectos clínicos. O projeto de universalização perde um vetor importante baseado na solidariedade e no papel redistributivo do poder federal, e o horizonte da integralidade recua ainda mais. O projeto de privatização ganha, com a capitação por pessoa cadastrada, somada à lista de serviços definida na CaSAPS, instrumentos importantes para a precificação - condições para a remuneração de serviços contratados, em especial ao setor privado.

Paralelamente, institui-se a ADAPS, entidade de direito privado, com leque amplo de poderes para atuação na atenção básica, que inclui a prestação e contratação de serviços; a formação de profissionais; a realização de pesquisa; e a incorporação de tecnologias. Apresentada como alternativa à gestão pública, a ADAPS escancara as intenções de privatização da atenção básica.

Tal processo político foi ancorado na interlocução com os colegiados de gestores, apartando da discussão os fóruns de controle social do SUS e buscando legitimidade em meios supostamente participativos, como a consulta pública. Esse instrumento tem sido frequentemente usado no ambiente político como meio de coleta de opiniões. Contudo, sem prever mecanismos de prestação de contas do que é coletado, prejudica a transparência e favorece a seleção e a utilização dos resultados em favor da pauta política dos gestores que a controlam. Além disso, tem substituído a participação presencial e representativa, prejudicando o debate público e ocultando os dissensos.

Confrontados com os limites impostos às políticas públicas pela EC 9537 e pelos efeitos nocivos à classe trabalhadora produzidos pelas contrarreformas trabalhista e previdenciária, os argumentos que defendem a necessidade e a positividade do pacote de medidas formuladas não demoram em se mostrar falaciosos. Ricos em retórica, não conseguem esconder, ao olhar crítico, os problemas no sentido e no modo de fazer a política.

A natureza das propostas e o modo como são apresentadas e justificadas evocam a imagem do Cavalo de Troia, o presente grego dado aos troianos que levou ao interior da cidade os meios para a conquistar. Embrulhadas para presente, as mudanças que tais medidas comportam são apresentadas como meio para a solução dos problemas de autonomia da gestão local, de resolutividade, acesso, eficiência e eficácia da atenção básica. Desembrulhadas, revelam o potencial de acelerar e aprofundar a privatização e a renúncia do SUS aos princípios que, articulados, formam sua principal frente de luta: o direito universal e igualitário à saúde - promovido com base na equidade -, a integralidade da atenção e a participação popular. 


\section{Colaboradores}

Todas as autoras contribuíram com a concepção do estudo, análise dos dados e redação do manuscrito.

\section{Informações adicionais}

ORCID: Marcia Valeria Guimarães Cardoso Morosini (0000-0001-6720-3150); Angelica Ferreira Fonseca (0000-0003-1694-1959); Tatiana Wargas de Faria Baptista (0000-0002-3445-2027).

\section{Referências}

1. Brasil. Constituição da República Federativa do Brasil. Diário Oficial da União 1988; 5 out.

2. Bahia L, Scheffer M. O SUS e o setor privado assistencial: interpretações e fatos. Saúde Debate 2018; 42(n.spe 3):158-71.

3. Correia MV, Santos VM. Privatização da saúde via novos modelos de gestão: as Organizações Sociais em questão. In: Bravo MIS, Andreazzi MFS, Menezes JSB, Lima JB, Souza RO, organizadores. A mercantilização da saúde em debate: as Organizações Sociais no Rio de Janeiro. Rio de Janeiro: Universidade do Estado do Rio de Janeiro/Rede Sirius; 2015. p. 33-9.

4. Turino F, Sodre F. Organizações sociais de saúde financiadas por emendas parlamentares. Trab Educ Saúde 2018; 16:1201-19.

5. Reis AAC, Sóter APM, Furtado LAC, Pereira SSS. Tudo a temer: financiamento, relação público e privado e o futuro do SUS. Saúde Debate 2016; 40(n.spe):122-35.

6. Ocké-Reis CO. Desafios da reforma sanitária na atual conjuntura histórica. Saúde Debate 2017; 41:365371.

7. Ministério da Saúde. Portaria no 2.436 , de 21 de setembro de 2017. Aprova a Política Nacional de Atenção Básica, estabelecendo a revisão de diretrizes para a organização da Atenção Básica, no âmbito do Sistema Único de Saúde (SUS). Diário Oficial da União 2017; 22 set.

8. Morosini MVG, Fonseca AF, Lima LD. Política Nacional de Atenção Básica 2017: retrocessos e riscos para o Sistema Único de Saúde. Saúde Debate 2018; 42:11-24.

9. Baptista TWF, Fausto MCR, Cunha MS. Análise da produção bibliográfica sobre atenção primária à saúde no Brasil em quatro periódicos selecionados. Physis (Rio J.) 2009; 19:1007-28.

10. Cueto M. O legado de Alma-Ata, 40 anos depois. Trab Educ Saúde 2018; 16:845-8.

11. Giovanella L, Mendonça MHM, Buss PM, Fleury S, Gadelha CAG, Galvão LAC, et al. De Alma-Ata a Astana. Atenção primária à saúde e sistemas universais de saúde: compromisso indissociável e direito humano fundamental. Cad Saúde Pública 2019; 35:e00012219.

12. Ministério da Saúde. Portaria no 2.979, de 12 de novembro de 2019. Institui o Programa Previne Brasil. Diário Oficial da União 2019; 13 nov.

13. Brasil. Medida Provisória no 890. Institui o Programa Médicos pelo Brasil, no âmbito da atenção primária à saúde no Sistema Único de Saúde, e autoriza o Poder Executivo federal a instituir serviço social autônomo denominado Agência para o Desenvolvimento da Atenção Primária à Saúde. Diário Oficial da União 2019; 1 ago.

14. Brasil. Lei no 13.958 , de 18 de dezembro de 2019. Institui o Programa Médicos pelo Brasil, no âmbito da atenção primária à saúde no Sistema Único de Saúde (SUS), e autoriza o Poder Executivo federal a instituir serviço social autônomo denominado Agência para o Desenvolvimento da Atenção Primária à Saúde (Adaps). Diário Oficial da União 2019; 19 dez. 
15. Ministério da Saúde. Carteira de Serviços da Atenção Primária à Saúde Brasileira. Avaliação por convidados externos e consulta pública. http://189.28.128.100/dab/docs/portaldab/ documentos/carteira_servico_da_APS_con sulta_SAPS.pdf (acessado em 15/Fev/2020).

16. Ministério da Saúde. Carteira de Serviços da Atenção Primária à Saúde (CaSAPS). Versão profissionais de saúde e gestores - completa. http://189.28.128.100/dab/docs/portaldab/ documentos/casaps_versao_profissionais_ saude_gestores_completa.pdf (acessado em 15/Fev/2020).

17. Côrtes SV. Sistema de saúde: espaços decisórios e a arena política de saúde. Cad Saúde Pública 2009; 25:1626-33.

18. Filippon J. A abertura da saúde nacional ao capital estrangeiro: efeitos do mercado global no Brasil. Saúde Debate 2015; 39:1127-37.

19. Ministério da Saúde. Portaria no 2.539, de 26 de setembro de 2019. Institui a equipe de Atenção Primária - eAP e dispõe sobre o financiamento de equipe de Saúde Bucal - eSB com carga horária diferenciada. Diário Oficial da União 2019; 27 set.

20. Ministério da Saúde. Portaria no 3.222, de 10 de dezembro de 2019. Dispõe sobre os indicadores do pagamento por desempenho, no âmbito do Programa Previne Brasil. Diário Oficial da União 2019; $11 \mathrm{dez}$.

21. Ministério da Saúde. Portaria no 3.510, de 18 de dezembro de 2019. Institui incentivo financeiro de custeio adicional mensal para municípios com equipes de saúde integradas a programas de formação profissional no âmbito da atenção primária à saúde. Diário Oficial da União 2019; 19 dez.

22. Departamento de Saúde da Família, Secretaria de Atenção Primária à Saúde, Ministério da Saúde. Nota Técnica no 3, de janeiro de 2020. Dispõe sobre Núcleo Ampliado de Saúde da Família e Atenção Básica (NASF-AB) e Programa Previne. https://portalarquivos 2 . saude.gov.br/images/pdf/2020/fevereiro/21/ SEI-MS---0013484477---Nota-T--cnica.pdf (acessado em 15/Fev/2020).

23. Ministério da Saúde. Portaria no 99, de 7 de fevereiro de 2020. Redefine registro das equipes de atenção primária e saúde mental no Cadastro Nacional de Estabelecimentos de Saúde (CNES). Diário Oficial da União 2020; 11 fev.

24. Harvey D. O novo imperialismo. 8a Ed. São Paulo: Edições Loyola; 2014.

25. Noronha JC, Lima LD, Machado CV. O Sistema Único de Saúde? SUS. In: Giovanella L, Escorel S, Lobato LVC, Noronha JC, Carvalho AI, organizadores. Políticas e sistema de saúde no Brasil. Rio de Janeiro: Editora Fiocruz; 2012. p. 365-93.

26. Rede de Pesquisa em Atenção Primária à Saúde da Abrasco. Contribuição para uma agenda política estratégica para a Atenção Primária à Saúde no SUS. Saúde Debate 2018; 42 (n.spe 1):406-30.
27. Castro ALB, Lima LD, Machado CV. Financiamento da atenção primária à saúde no Brasil. In: Mendonça MHM, Matta GC, Gondim R, Giovanella L, organizadores. Atenção Primária à Saúde no Brasil: conceitos, prática e pesquisa. Rio de Janeiro: Editora Fiocruz; 2018. p. 7393.

28. Ministério da Saúde. Saúde da família no Brasil: uma análise de indicadores selecionados: 1998-2004. Brasília: Ministério da Saúde; 2006.

29. Ministério da Saúde. Sala de Apoio à Gestão. http://sage.saude.gov.br/\# (acessado 15/ $\mathrm{Fev} / 2020$ ).

30. Macinko J, Guanais FC, Souza MDFM. Evaluation of the impact of the Family Health Program on infant mortality in Brazil, 1990-2002. J Epidemiol Community Health 2006; 60:13-9.

31. Campos RTO, Ferrer AL, Gama CAP, Campos GWS, Trapé TL, Dantas DV. Avaliação da qualidade do acesso na atenção primária de uma grande cidade brasileira na perspectiva dos usuários. Saúde Debate 2014; 38(n.spe):25264.

32. Facchini LA, Tomasi E, Dilelio AS. Quality of primary health care in Brazil: advances, challenges and perspectives. Saúde Debate 2018; 42(n.spe 1):208-23.

33. Mendes A, Carnut L, Guerra LDS. Reflexões acerca do financiamento federal da atenção básica no Sistema Único de Saúde. Saúde Debate 2018; 42 (n.spe 1):224-43.

34. Ministério da Saúde. Portaria no 3.992, de 28 de dezembro de 2017. Dispõe sobre o financiamento e a transferência dos recursos federais para as ações e os serviços públicos de saúde do Sistema Único de Saúde. Diário Oficial da União 2017; 28 dez.

35. Massuda A. Mudanças no financiamento da atenção primária à saúde no Sistema de Saúde Brasileiro: avanço ou retrocesso? Ciênc Saúde Coletiva 2020; 25:1181-8.

36. Mendes A, Carnut L. Novo modelo de financiamento para qual Atenção primária à saúde? Domingueira da Saúde 2019; (36). http:// idisa.org.br/domingueira/domingueira-n-36outubro-2019?lang=pt.

37. Brasil. Emenda Constitucional no 95, de 15 de dezembro de 2016. Altera o Ato das Disposições Constitucionais Transitórias, para instituir o Novo Regime Fiscal, e dá outras providências. Diário Oficial da União 2016; 16 dez.

38. Instituto Brasileiro de Geografia e Estatística. Classificação e caracterização dos espaços rurais e urbanos do Brasil: uma primeira aproximação. Rio de Janeiro: Instituto Brasileiro de Geografia e Estatística; 2017.

39. Conselho de Secretarias Municiapais de Saúde do Estado do Rio de Janeiro. Análise da proposta de mudança na modalidade de transferência de recursos para atenção primária à saúde apresentada pelo Ministério da Saúde. Rio de Janeiro: Conselho de Secretarias Municiapais de Saúde do Estado do Rio de Janeiro; 2019. 
40. Melo EA, Almeida PF, Lima LD, Giovanella L. Reflexões sobre as mudanças no modelo de financiamento federal da atenção básica à saúde no Brasil. Saúde Debate 2019; 43 (n.spe):137-44.

41. Mandetta LH, Guedes PRN. Medida Provisória no 890, de 01 de agosto de 2019. Exposição de motivos. https://www2.camara.leg. $\mathrm{br} /$ legin/fed/medpro $/ 2019 / \mathrm{medidaproviso}$ ria-890-1-agosto-2019-788911-exposicao demotivos-158846-pe.html (acessado em 15/ $\mathrm{Fev} / 2020$ ).

42. Giovanella L, Bousquat A, Almeida PF, Melo EA, Medina MG, Aquino R, et al. Médicos pelo Brasil: caminho para a privatização da atenção primária à saúde no Sistema Único de Saúde? Cad Saúde Pública 2019; 35:e00178619.

43. Ruschi A. Palavra do presidente: Alexandre Ruschi escreve sobre o novo programa do governo "Médicos pelo Brasil". https://www. unimed.coop.br/web/cnu-central/publica coes/palavra-do-presidente-alexandre-rus chi-escreve-sobre-o-novo-programa-do-go verno-medicos-pelo-brasil- (acessado em 15/ Fev/2020)
44. Escola Politécnica de Saúde Joaquim Venâncio. Proposta de carteira de serviços da atenção primária divide opiniões. http://www.epsjv. fiocruz.br/noticias/reportagem/proposta-decarteira-de-servicos-da-atencao-primaria-di vide-opinioes (acessado em 15/Fev/2020).

45. Rede de Pesquisa em Atenção Primária à Saúde da Abrasco. Posicionamentos sobre a Carteira de Serviços da APS. https://redeaps.org. br/2019/09/09/posicionamentos-sobre-acarteira-de-servicos-da-aps/ (acessado em 03/ Dez/2019).

46. Gondim GMM, Monken M. O uso do território na atenção primária à saúde. In: Mendonça MHM, Matta GC, Gondim R, Giovanella L, organizadores. Atenção Primária à Saúde no Brasil: conceitos, prática e pesquisa. Rio de Janeiro: Editora Fiocruz; 2018. p. 143-75.

47. Mattos RA. A integralidade na prática (ou sobre a prática da integralidade). Cad Saúde Pública 2004; 20:1411-6. 


\section{Abstract}

The essay analyzes documents produced by the Brazilian Ministry of Health in 2019 and 2020 for the reorganization of basic healthcare: the new financing policy (Previne Brasil), the Agency for the Development of Primary Healthcare (Law $\mathrm{n}$. 13,958), the Services Portfolio, and complementary provisions. The objective was to understand how the projected changes in management roles and the healthcare model contribute to strengthening the public policy's mercantile logic. As parameters for the analysis, we used the management responsibilities and the principles and guidelines of the Brazilian Unified National Health System (SUS) and basic healthcare oriented according to the social determination of the health-disease process, the expanded definition of health, territorially organized care, community focus, and coordination of care in an integrated network. Changes in the allocation of public resources, the establishment of new possibilities for relations between the State and private companies, and adjustment of the healthcare model to market management characteristics reveal the privatizing orientation of these measures. The policy assumes an individualizing focus in the model of care and financing, undercutting the territorial perspective, community work, and comprehensive and multidisciplinary care. This accelerates the reconfiguration of the SUS as a system in which public or private agents can participate indistinguishably, exacerbating the break with the constitutional commitment to health as a duty of the State.

Health Management; Heath Policy; Family Health Strategy; Unified Health System; Primary Health Care

\section{Resumen}

El ensayo analiza documentos producidos por el Ministerio de Salud entre 2019 y 2020 para la reorganización de la atención básica: la nueva política de financiación (Previne Brasil), la Agencia de Desarrollo de la Atención Primaria a la Salud (Ley no 13.958), la Cartera de Servicios y normativas complementarias. Se buscó comprender de qué forma los cambios proyectados en las funciones gestoras y en el modelo de atención en salud contribuyen al fortalecimiento de la lógica mercantil en la política pública. Tomamos como parámetros de análisis las atribuciones gestoras y los principios y directrices del Sistema Único de Salud (SUS) y de una atención básica orientada por la determinación social del proceso salud/enfermedad, la concepción ampliada de salud, el cuidado territorializado, el enfoque comunitario y la coordinación del cuidado en una red integrada. Los cambios en la asignación de los recursos públicos, el establecimiento de nuevas posibilidades de relación entre el Estado y empresas privadas, así como la adecuación del modelo de atención a las particularidades de la gestión de mercado, revelan el sentido privatizador de estas medidas. La política asume un enfoque individualizador, en lo que atañe al modelo de atención y financiación, debilitando la perspectiva del territorio, el trabajo comunitario, el cuidado integral y multidisciplinario. Se acelera la reconfiguración del SUS como sistema en el que agentes públicos o privados pueden participar, indistintamente, profundizando la ruptura con el compromiso constitucional de la salud como deber de Estado.

Gestión en Salud; Política de Salud; Estrategia de Salud Familiar; Sistema Único de Salud; Atención Primaria de Salud
Recebido em 03/Mar/2020

Versão final reapresentada em 15/Jun/2020

Aprovado em 21/Jun/2020 